\title{
A CLINICAL STUDY OF THE ABDOMINAL SKIN REFLEXES IN NEWBORN INFANTS
}

\author{
BY \\ OLE K. HARLEM and ARVE LÖNNUM \\ From the Departments of Neurology, Obstetrics and Paediatrics, Oslo University Hospital (Rikshospitalet), Norway
}

(RECEIVED FOR PUBLICATION OCTOBER 26, 1956)

The abdominal skin reflexes have been shown to be present in children and adults with a definite pattern of such constant appearance that they play a part in the routine clinical examination (MunchPetersen, 1901; Müller and Seidelmann, 1905; Söderbergh, 1918). But, according to well known text-books on neurology and paediatrics, the examination of the abdominal skin reflexes in the newborn and infants is of very little clinical value because of their inconstant pattern. This common view may be illustrated by the following quotation from Ford (1952):

'The abdominal reflexes may be elicited in the newborn in about one-third of all cases. The reflex obtained at this age is a rather diffuse reaction often involving the extremities and probably essentially different from the adult response. Some time between the sixth month and the end of the first year the true abdominal responses should appear.'

DeJong (1955), Ellis (1951) and Nelson (1954) express a similar view.

The abdominal reflexes encountered in children and adults are by many authors supposed to be neo-flexes, that is, reflexes developed late in infancy and dependent on the functional state of the pyramidal tract (Bychowski, 1908; Monrad-Krohn, 1950). Most publications report findings supporting the view expressed by the authors previously mentioned.

Munch-Petersen (1901) could not elicit the abdominal reflexes in 19 of 65 children up to 2 years old, but he did not especially emphasize the findings in the newborn period. Cattaneo (1902) found the abdominal reflexes to be absent in the first month of life. In infants 5 to 90 days old he could find these reflexes present in $35 \%$ only. Laurent (1905) concluded after his investigation of 34 infants in the group aged 0 to 3 months that the abdominal reflexes are absent or weak in newborn infants. Bychowski (1908) examined 39 infants under $2 \frac{1}{2}$ years old, and found abdominal reflexes in only four of them. He claimed that these reflexes are not present at birth. Monrad-Krohn (1918) observed abdominal reflexes in about onethird of the infants examined. Griffith and Mitchell (1927) stated that according to Burr (1921), who examined 20 infants and found the reflexes absent in seven, the abdominal reflexes appear irregularly. Chaney and McGraw (1932) examined 25 newborn infants immediately after birth, finding abdominal reflexes in only two. Further, they examined 100 infants from 2 to 35 hours old, and observed these reflexes in only $33 \cdot 3 \%$, without being able to explain this low frequency. André-Thomas, Chesni and St. Anne Dargassies (1954) stated that the abdominal reflexes are not present in the first 10 days of life.

On the other hand, some authors report findings which indicate that the abdominal reflexes are present from birth. Goldflam (1912) examined 30 infants from 9 days to 1 year old. He elicited abdominal reflexes in all of them. He did not, however, describe the character of the response in detail. De Angelis (1923) examined 87 infants in the first week of life, most of them under 2 days old. $\mathrm{He}$ stated that, by waiting patiently for the right moment, one might succeed in eliciting all reflexes in the newborn. It seemed to us improbable that the abdominal reflexes should behave differently from other reflexes, and appear at an age when reflex activity otherwise diminishes, and a preliminary investigation of 28 infants in the Department of Paediatrics, Oslo University Hospital, seemed to indicate that abdominal reflexes of a definite pattern were constantly present in early infancy (Lönnum, 1956).

This and the previously reported investigations concerning the abdominal skin reflexes in infancy covered a comparatively small number of infants, and as the reports did not satisfactorily describe the responses in detail, a more comprehensive study was considered necessary.

The present study was undertaken with two 
objects in view: (1) To examine the frequency of the abdominal reflexes in early infancy in a sufficiently great number of infants. (2) To get information of the character of these reflexes at this age.

\section{Material}

Two hundred healthy, full-term infants, 112 boys and 88 girls, were examined in the Department of Obstetrics of Oslo University Hospital. The youngest was 2 hours old, the oldest 7 days old. More than $50 \%$ were from 2 to 4 days old. The length of the boys varied from 43 to $57 \mathrm{~cm}$., with an average of $51.5 \mathrm{~cm}$. The average weight in this group was $3,475 \mathrm{~g}$., varying from 1,770 (in the smallest twin) to $4,860 \mathrm{~g}$. The average length of the girls was $50 \mathrm{~cm}$., varying from 46 to $56 \mathrm{~cm}$., and the average weight in this group was $3,435 \mathrm{~g}$., varying from 2,480 to $4,480 \mathrm{~g}$.

\section{Methods}

To obtain ideal conditions for the examination of the abdominal reflexes, the following examination alone was done.

The baby was placed on the nursing table in a quiet, warm room and was handled by a trained nurse. Uneasy or crying infants were given a nipple dipped in glucose solution. The abdominal reflexes were examined with the technique described by Monrad-Krohn (1918). For routine stimulus a blunt needle was used with strokes applied along the costal margin, in the supra-umbilical, umbilical and infra-umbilical region.

\section{Results}

Under such conditions and with this technique the abdominal reflexes were found to be present with a definite pattern in all the 200 infants examined.

A typical response consists of a segmental, homoand uni-lateral deviation of the linea alba, of exactly the same character as in adults. There is further a curving of the trunk to the stimulated side, as observed in some cases by Monrad-Krohn (1918) and others. This curving is the result of a simultaneous visible and palpable contraction of the rectus abdominis muscle and the homolateral erector trunci muscle. There is a marked tendency to bilateral responses and to a retraction of the abdominal wall. The responses are more extensive and the reflexogenous zone is wider than in adults.

Almost immediately after the response described, a flexion in the homolateral leg or in both legs is observed, consisting of the same motor components as the well-known flexion reflex under pathological conditions. However, this flexion reflex in infants is characterized by shorter latency and duration than the pathological flexion reflex.

In some cases a series of pinpricks and spatula strokes were used as stimuli. The same responses were obtained as with the blunt needle which, however, was used as the routine stimulus for three reasons: (1) This stimulus was used in most of the earlier investigations of these reflexes. (2) It is preferred by most clinicians in the routine clinical examination. (3) It was found to be the most effective.

Sometimes the reflexes were readily elicited, but often one had to wait for minutes to obtain the right moment for applying the stimulus. The reflexes were weak in some cases, especially in uneasy infants and in infants with dry skins. In such cases a brisk response could be obtained after soothing the infant or after oiling the skin. Weak abdominal reflexes were also observed in infants with distended abdomen. In these cases the examiner had to wait until the distension was reduced.

Sometimes the segmental response was more readily elicited, sometimes the curving of the trunk or the flexion reflex. These partial responses were, however, in no way different from the reactions described in the typical response.

\section{Discussion}

Our investigation confirms the observations of Goldflam (1912) and De Angelis (1923) that the abdominal reflexes in man are present from birth. It does not support the view commonly expressed in text-books on neurology and paediatrics, probably based on the observations of Munch-Petersen (1901), Cattaneo (1902) and others. The discrepancies between the findings of the investigators mentioned earlier and ours might be explained partly by differences in methods.

The abdominal reflexes only were examined in the present investigation, whereas most of the aforementioned investigators seem to have made it a part of a broader examination. During a prolonged examination of an infant it is very difficult to keep optimal conditions throughout, and some of the results will necessarily be unreliable. In some cases we could not at first obtain good results because the infant was uneasy or cried, and therefore had to watch for the right moment. In other cases, a distended abdomen or a dry skin prevented a satisfactory response.

The positive result of our investigation may to some extent be dependent on the fact that our study was started on the presumption that the abdominal reflexes, as well as other reflexes, are present from birth. In doubtful cases this presumption would 
stimulate greater patience during the examination.

The abdominal skin reflexes observed in early infancy have been thought to be essentially different from the responses observed in children and adults. Our findings do not support this view. A comparison between the 'normal' adult response and that in infants indicates that the former is principally the same as the latter. The reflexogenous zone is narrower in adults and the response itself localized to muscles belonging to the stimulated segments. The most probable explanation of these facts is that in adults the response is inhibited compared with the response in infants. The abdominal reflexes therefore seem to be inhibited when cerebral control is developed as are other reflexes of the infant, e.g., the grasping reflex, the Moro reflex and the sucking reflex (Litvay, 1950; Lamote De Grignon, 1955). They cannot be neo-reflexes as Bychowski (1908) stated.

A curving of the trunk to the stimulated side is readily induced in infants by stroking the skin along the spine (Litvay, 1950). A similar curving was often observed when eliciting the abdominal reflexes. This reaction, which has earlier been described by Goldflam (1912), Monrad-Krohn (1918) and others, has in regards to stimulus, latency and duration much in common with the usual abdominal skin reflexes. The two reaction types are, therefore, in our opinion, of the same nature.

The abdominal skin reflexes have been thought to represent a reaction of defence (Karassik, 1924), but a defence reaction would most likely be the response to a nociceptive stimulus, whereas the abdominal skin reflexes are more readily elicited by a tactile stimulus (Monrad-Krohn, 1918). The response itself has the character of coordinated movements, as has the grasping reflex. The abdominal muscles have partly retained a segmental structure. It may be suggested that these primitive muscles have also retained primitive movement patterns. The abdominal reflexes may therefore represent remnants of segmental movements governed by external, tactile stimuli.

A flexion of the homolateral leg or of both legs was frequently observed simultaneously with, or immediately after, the abdominal reflexes. The motor components were the same as in the flexion reflex often elicited from the abdomen in adults in diseases of the central nervous system, especially in cases of transverse spinal lesion (Riddoch, 1917; Monrad-Krohn, 1925). However, the response in infants was of shorter latency and duration.

The difference in response may be explained by the presence of a supraspinal facilitating influence in infants, which is lost in patients with transverse spinal lesions. The abdominal, and particularly the flexion reflexes, are weakened in the course of infancy, probably because of the development of a central inhibitory mechanism. In certain cases of disease in the central nervous system in adults, a flexion reflex is observed simultaneously with brisk abdominal skin reflexes (Lönnum, 1956). This fact may be explained by a lesion which abolishes the inhibitory mechanism mentioned before.

From the work of Rosenbach (1876) it is known that the abdominal reflexes are altered in cases of cerebral lesions. It is therefore assumed that these reflexes are dependent on supraspinal structures. In the foetus abdominal reflexes have been observed which are supposed to be of purely spinal origin (Krabbe, 1912; Minkowski, 1923). However that may be in the foetus, the character of the abdominal reflexes in newborn infants is so similar to that in adults that a supraspinal influence must also be assumed at this stage. We have found abdominal reflexes absent in infants with cerebral lesions. This fact seems to corroborate the assumption that the abdominal reflexes in early infancy are dependent upon supraspinal structures.

As the pyramidal tract has been supposed to be necessary for the abdominal reflexes (MonradKrohn, 1950, and others), it has hitherto been difficult to explain the findings of brisk abdominal skin reflexes in diseases with lesions of this tract (Wartenberg, 1945). If the pyramidal tract really is essential to the abdominal reflexes, some fibres in it must necessarily function from birth. A lesion of these fibres may abolish the reflexes. According to the common view other fibres do not start functioning until about six months after birth. These fibres may be the transmitter of the inhibitory central influence upon the abdominal reflexes previously mentioned. A selective lesion of these fibres would explain the findings of brisk abdominal reflexes in cases of pyramidal tract involvement. Nathan and Smith (1955) have recently shown that the pyramidal tract is not the only tract of importance to the plantar reflex. This probably applies to the abdominal reflexes as well. Further clinical and experimental work is necessary to clarify the relationship between the abdominal reflexes and the pyramidal tract and other structures of the central nervous system.

\section{Summary}

According to well-known text-books on neurology and paediatrics, the abdominal skin reflexes in newborn infants are present only in a relatively small number of cases and are of an irregular pattern. 
All of 200 full-term healthy infants in the first week of life were found to have abdominal skin reflexes of a definite pattern.

The theories concerning the abdominal skin reflexes are discussed.

We extend our sincere thanks to the heads of the Departments of Obstetrics, Neurology and Paediatrics, Prof. E. Schjött-Rivers, Prof. S. Refsum and Prof. L. Salomonsen, for their kindness and helpful criticism, and to the sisters and nurses in the obstetric ward for their contribution to the successful results of the investigation. The technical assistance of Mr. E. Halvorsen was much appreciated.

\section{REFERENCES}

André-Thomas, Chesni, Y. and St. Anne Dargassies (1954). Vie méd., 35, Dec. Special No., p. 16.

Burr, C. W. (1921). Amer. J. Dis. Child., 21, 529.

Bychowski, Z. (1908). Dtsch. Z. Nervenheilk., 34, 116

Cattaneo, C. (1902). Jb. Kinderheilk., 55, 458.

Chaney, L. B. and McGraw, M. B. (1932). Bull. neurol. Inst. N.Y., $2,1$.

De Angelis, F. (1923). Amer. J. Dis. Child., 26, 211.
DeJong, R. N. (1955). In A. B. Baker's Clinical Neurology, vol. I, p. 65 . New York.

Ellis, R. W. B. (1951). Disease in Infancy and Childhood, p. 22. Edinburgh

Ford, F. R. (1952). Diseases of the Nervous System in Infancy, Childhood and Adolescence, 3rd ed., p. 61. Oxford.

Goldflam, S. (1912). Z. ges. Neurol. Psychiat., 8, 230.

Griffith, J. P. C. and Mitchell, A. G. (1927). The Diseases of Infants and Children, 2nd ed., vol. I, p. 61. Philadelphia and London.

Karassik, W. M. (1924). Pflügers Arch. ges. Physiol., 204, 549.

Krabbe, K. (1912). Rev. neurol. (Paris), (Oct.), 24, 434.

Lamote De Grignon, C. (1955). Ibid., 93, 217.

Laurent, R. (1905). Evolution des iéflexes chez l'enfant. Thése, Toulouse.

Litvay, E. (1950). Ann. paediat. (Basel), 174, 252.

Lönnum, A. (1956). Acta psychiat. neurol scand., 108, p. 243, Suppl.

Minkowski, M. (1923). Schweiz. Arch. Neurol. Psychiat. 13, 475.

Monrad-Krohn, G. H. (1918). On Abdominal Reflexes. Kristiania (Oslo).

(1925). Arch. Neurol. Psychiat. (Chicago), 13, 750

- (1950). Schweiz. Arch. Neurol Psychiat, 66, 338

Munch-Petersen, H. (1901). Hudreflexerne og deres Nervebaner. Copenhagen. Cited by Monrad-Krohn.

Müller, E. and Seidelmann, W. (1905). Münch. med. Wschr., 52, 1323.

Nathan, P. W. and Smith, M. C. (1955). Brain, 78, 248.

Nelson, W. E. (1954). Texthook of Pediatrics, 6th ed., p. 33. Philadelphia and London.

Riddoch, G. (1917). Brain, 40, 264.

Rosenbach, O. (1876). Arch. Psychiat. Nervenkr., 6, 845.

Söderbergh, G. (1918). Neurol. Zbl., 37, 234.

Wartenberg, R. (1945). The Examination of Reflexes. Chicago. 